\title{
ICTAL ECG CHANGES IN TEMPORAL LOBE EPILEPSY
}

\author{
L.M.LI*, J. ROCHE** J.W.A.S. SANDER***
}

SUMMARY - Changes in cardiac rhythm may occur during epileptic seizures and this has been suggested as a possible mechanism for sudden unexpected death amongst patients with chronic epilepsy (SUDEP). We have studied ECG changes during 61 complex partial seizures of temporal lobe origin in 20 patients. Tachycardia was observed in 24/61 (39\%) and bradycardia in 3/61 (5\%). The mean and median tachycardia rate was 139 and 140 beats/min (range 120-180). The longest R-R interval observed was 9 seconds. No difference was found in regard to the lateralisation of seizures and cardiac arrhytmia. One of the patients with bradycardia was fitted with a demand cardiac pacemaker, which appeared to decrease the number of his falls. In conclusion, ictal cardiac changes which may be seen in temporal lobe epilepsy (TLE) are sinus tachycardia and occasionally sinus bradycardia. Patients presenting vague complains suggestive of either TLE or cardiac dysrhythmia, simultaneous monitoring with EEG/ECG is required, and if the episodes are frequent, video-EEG should be considered. Further studies on this subject are warranted as this may shed some light on possible mechanisms for SUDEP.

KEY WORDS: epilepsy, cardiac arrhythmia, sudden death.

\section{Alteraçōes eletrocardiográficas ictais em epilepsia do lobo temporal}

RESUMO - Alteraçōes no ritmo cardíaco podem ocorrer durante crises epilépticas. Estas alterações têm sido sugeridas como possível mecanismo para explicar morte súbita em pacientes com epilepsia crônica. Analisamos o eltrocardiograma (ECG) em 61 crises parciais complexas do lobo temporal de 20 pacientes. Taquicardia foi observada em 24/61 (39\%) e bradicardia em 3/61 (5\%). A média e a mediana da taquicardia foram 139 e 140 batimentos por minuto (variando de 120-180). $\mathrm{O}$ intervalo $\mathrm{R}-\mathrm{R}$ mais longo foi 9 segundos. Năo houve diferença em relação a lateralisaçāo das crises e alteração do ritmo cardíaco. Um paciente com bradicardia recebeu marcapasso de demanda, com diminuiçāo importante das suas quedas durante as crises. Em conclusão, as alterações cardíacas ictais em crises do lobo temporal mais comuns são taquicardia sinusal e menos frequentemente bradicardia. Em pacientes com queixas vagas que sugerem tanto epilepsia e arritmia cardíaca, monitorização simultânea com EEG/ECG é recomendada e se as crises forem frequentes, vídeo-EEG deve ser considerado. Estudos nesta área são necessários para esclarecimento de possíveis mecanismos da morte súbita em pacientes com epilepsia.

PALAVRAS-CHAVE: epilepsia, arritmia cardíaca, morte súbita.

Epilepsy is a common neurological condition with a prevalence of 5-10 cases per 1000 people $^{6,19}$. Chronic epilepsy has been associated with an increased risk of sudden unexpected death

Epilepsy Research Group, Institute of Neurology, Queen Square, London, WCIN 3BG, and the National Hospital for Neurology and Neurosurgery, Chalfont Centre for Epilepsy, Chalfont St. Peter, Bucks., SL9 ORJ, UK: *MD, Research Fellow in Clinical Neurophysiology; ${ }^{* *}$ Tecnician in Clinical Neurophysiology; ***MD PhD, Consultant Neurologist. Aceite: 6-maio-1995. 
(SUDEP) when compared to the general population ${ }^{10,15}$. An annual mortality rate of 1 SUDEP for 200-370 people with chronic uncontrolled epilepsy has becn suggested ${ }^{11,16}$. The mechanism of SUDEP is not clear, and autonomic changes affecting the cardiac rhythm, deleterious action of antiepileptic drugs, and the release of endogenous opiates affecting the respiratory centre have been advanced as possible mechanisms ${ }^{10}$. Autonomic changes may occur as manifestations of epileptic seizures. In daily clinical practice, however, these changes are not commonly recognised or documented, especially with regard to cardiac rhytms. With the advent of simultaneous EEG and ECG recording, different types of ictal cardiac dysrhythmia have been reported ${ }^{9,17}$, and this has given some insight about a possible mechanism for SUDEP. Simple or complex partial seizures show no concomitant EEG changes in approximately $20-40 \%$ of cases ${ }^{4,12}$, and this may potentially give a misleading interpretation of simultaneous EEG/ECG recording if the correct timing of clinical onset is unclear.

The aim of this study was to ascertain ictal ECG changes in a selected group of patients with chronic temporal lobe epilepsy (TLE) recorded during pre surgical assessment at the video EEG monitoring Unit of the National Hospital for Neurology and Neurosurgery.

\section{PATIENTS AND METHODS}

Twenty patients ( 11 females, 9 males) were randomly selected from a group of 100 consecutive patients with refractory TLE referred for pre surgical assessment. None of them had a history of cardiac dysfunction, and cardiac examination and routine ECG were normal in all cases. The median age was 28 years (range 16-47).

Simultaneous EEG and ECG were recorded digitally using a computer based system. All patients had a diagnosis of unilateral hippocampal sclerosis, which was based on clinical grounds, EEG and volumetric MRI (1.5 Tesla) ${ }^{3}$ except for one patient who had a white matter lesion of uncertain nature in the temporal lobe. Seizures were right sided in 12 patients and left sided in 8 . Tachycardia and bradycardia were defined as more than 120 and less than 50 beats/min respectively. Increase in heart rate was defined as an increase of more than $10 \%$ of baseline heart rate just before the clinical seizure onset.

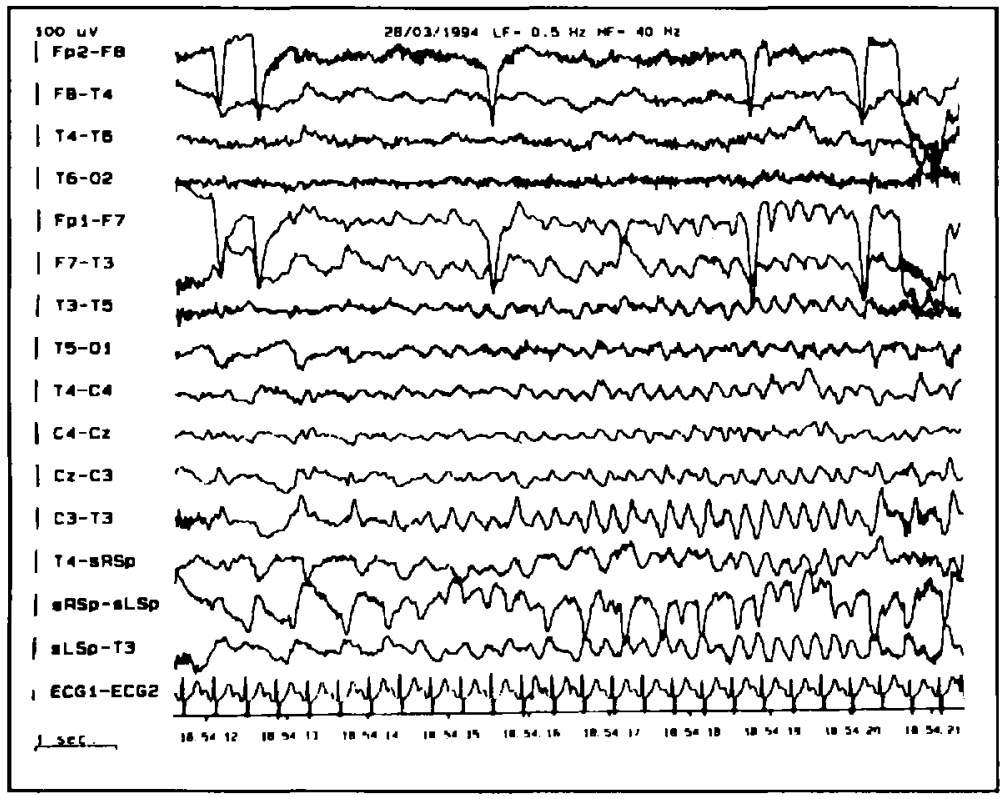

Fig 1. EEG shows rhythmical activity over left hemisphere, maximum in the anteromesial temporal region. ECG (lead l) shows sinus tachycardia at 168 beats/min. 


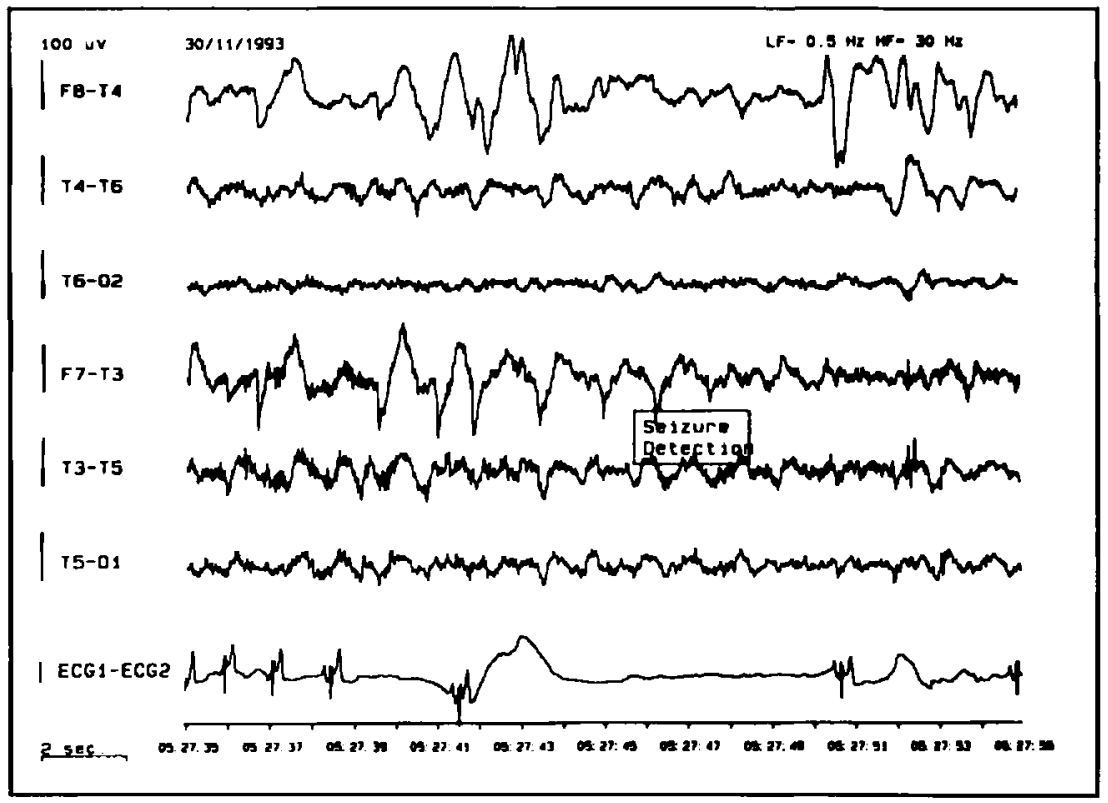

Fig 2. ECG shows a progressive sinus bradycardia with a pause of up to 9 seconds between $R-R$ intervals.

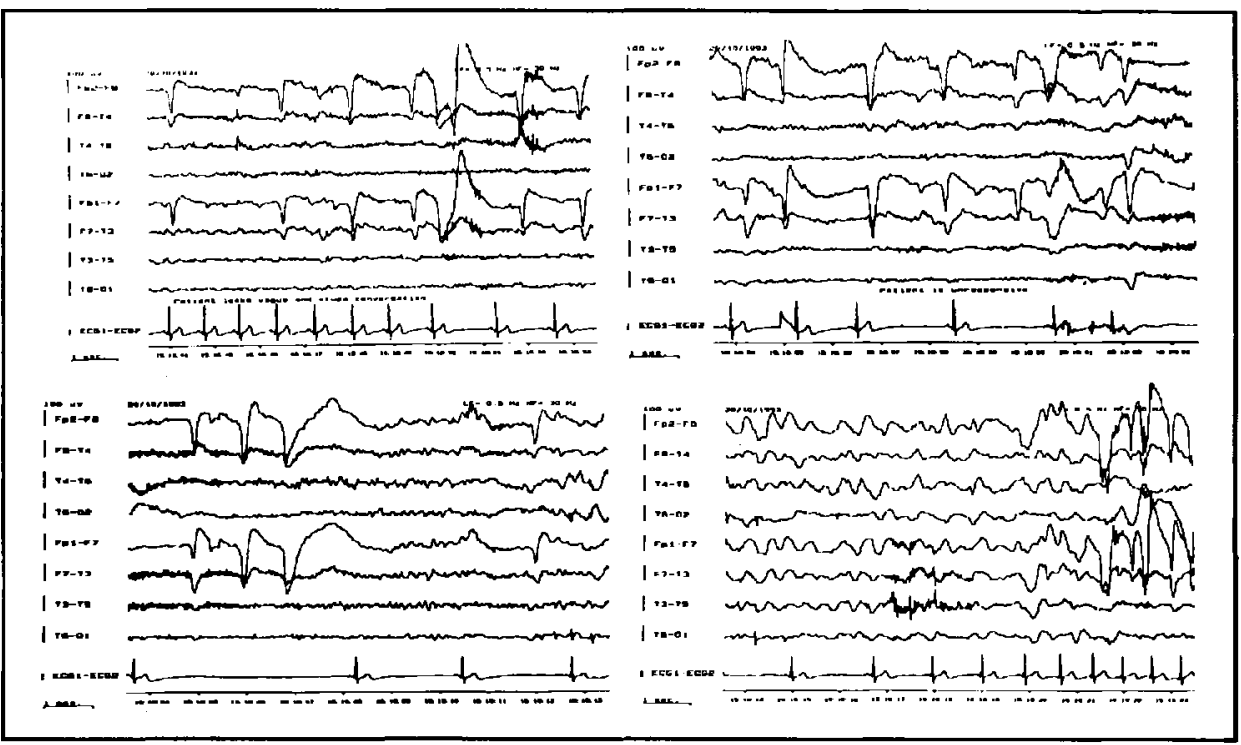

Fig 3. The patient's habitual attack precedes the progressive sinus bradycardia. The concomitant EEG shows equivocal underlying semi rhythmical slow activity over the left temporal region at the clinical onset. Towards the end of the attack, the EEG shows widespread anterior predominant delta activity, associated with clinical hypotonia, probably reflecting cerebral hypoperfusion. Afterwards, the ECG shows a progressive recovery. 


\section{RESULTS}

Sixty one clinical attacks were recorded. The ictal EEGs and ECG (lead I) traces were reviewed. The clinical features were those of comlex partial seizures of temporal lobe ${ }^{21}$, and one patient had a secondary generalised tonic clonic seizure.

Increase of heart rate were observed in $55(90 \%)$ attacks. Significant ECG changes were observed in 27/61 seizures: tachycardia was seen in $24 / 61$ (39\%) and bradycardia in $3 / 61$ (5\%). The mean and median tachycardia rate was 139 and 140 beats/min (range 120-180) (Fig 1). The longest R-R interval was 9 seconds (Fig 2).

No difference was seen in regard with seizures lateralization and type of cardiac dysrhythmia albeit the numbers were small.

One of the ictal ECG was of interest (Fig 3). Clinically, the patient stopped his conversation, became vague and detached. His wife recognised the event as his typical attack. After the clinical onset, the EEG showed no definite changes, but the ECG showed progressive bradycardia. Then, the patient became hypotonic and the EEG showed widespread anterior predominant rhythmical delta waves probably reflecting cerebral hypoperfusion, and the ECG showed a progressive recovery. The patient was not considered a surgical candidate for other reasons. In view of the frequency of attacks and the concomitant ictal bradycardia, a demand pacemaker was fitted. This lead to a significant decrease in the number of his falls (> 50\%), within 6 months of follow up.

\section{COMMENTS}

Changes in cardiac thythm have been implicated as cause and the consequence of seizures disorders. Cerebral hypoperfusion due to cardiac arrest lasting more than 4 seconds, bradycardia $(<$ 40 beats $/ \mathrm{min}$ ), or tachycardia ( $>150$ beats $/ \mathrm{min}$ ), my lead to variety of cerebral symptoms ${ }^{22}$. It has been reported that patients referred to specialised centres for assessment of chronic epilepsy turn out to have underlying cardiac dysfunction in approximately $20-30 \% \%^{5,20,24}$.

Experimental and clinical data have shown that cardiac rhythm may change during epileptic attacks, and this is dependent on the type of seizures ${ }^{7,8,23}$. The ictal ECG changes observed in this study were tachycardia and less frequently bradycardia, which is similar to previous studies ${ }^{1,7,9,17}$. Mechanisms of cardiac arrhythmia suggested in temporal lobe epilepsy include the spread of epileptic activity to autonomic centre ${ }^{13,23}$, and emotional autonomic reaction in response to an aura ${ }^{8}$. The ECG changes, however, may occur either in subclinical or clinical attacks or even in cases without aura ${ }^{2,7}$ in which case the latter mechanism seems unlikely as a primary cause, but in some cases may play an adjuvant role in ictal tachyarrhythmia.

Differentiating between TLE and cardiac dysfunction may not be easy in some cases, as clinical features of TLE may not be florid and may overlap with symptoms and signs of cardiac dysfunction. Assessment of these cases just based on ECG (Holter) without concomitant EEG may be misleading, as some cases of TLE with cardiac involvement may be considered primarily as a cardiac dysfunction instead of secondary to seizures. In a study carried out in a cardiac pacemaker clinic, patients referred were monitorized using simultaneous EEG and ECG, showed that $83 \%$ of patients with complex partial seizures might have been incorrectly diagnosed on referral ${ }^{1}$. This suggests that patients with a vague history that hints either of an epileptic or a cardiac nature, simultaneous EEG/ECG monitoring is required. If the patient's seizures are frequent, video-EEG is therefore the choice, as in some cases of partial complex seizures scalp EEG may show no interictal changes.

The mechanism of SUDEP is uncertain, and secondary cardiac dysrhythmia appears to be an attractive explanation, however, experimental studies in animal models have shown taht changes in 
cardiac rhythm secondary to epileptic discharges involving subcortical nucleus were unable to lead to death in the experimental animal unless other concomitant factors were present, such as metabolic disturbances $^{13}$.

AEDs are known to cause changes in cardiac rhythm ${ }^{18}$. However, as far as SUDEP is concerned, it seems that they are unrelated, as SUDEP has been well described before the advent of any of the modern AEDs ${ }^{14}$.

In conclusion, evaluation of patients with a long history of vague symptoms suggesting either an epileptic or a cardiac cause, who have been carefully investigated, concomitant ECG/EEG or video-EEG is worthwhile. Patients with well documented ictal bradycardia, and who are not surgical candidates, may be considered for a demand pacemaker. Further studies on this area are urgently warranted as this may shed light on possible mechanism for SUDEP.

Acknowledgement - We would like to thank Dr. Lina Nashef and Dr. Michael O'Donoghue for their comments and the Telemetry Unit staff for data assistance. Dr. Li Li Min is grateful for support from the National Society for Epilepsy, United Kingdom.

\section{REFERENCES}

1. Blumhardt LD, Smith PEM, Owen L. Electrocardiographic accompaniments of temporal Jobe epileptic seizures. Lancet 1986, 10:1051-1056.

2. Burr W, Bulau P, Elger CE. Does rapid increase in heart rate during sleep support the diagnosis of complex partial seizure? J Epilepsy 1994, 7:321-323.

3. Cook MJ, Fish DR, Shorvon SD, Starughan K, Stevens JM. Hippocampal volumetric and morphometric studies in temporal and frontal lobe epilepsy. Brain 1992, 115:1001-1015.

4. Devinsky O, Kelly K, Porter R, Theodore WH. Clinical and electrographic features of simple partial seizures. Neurology 1988, 38:1347-1352.

5. Gastaut H. Syncopes: generalised anoxic cerebral seizures. In Vinken PJ, Bruyn GW (eds). Handbook of clinical neurology, Vol 15. Amsterdam: North Holland, 1974: 815-823.

6. Goodridge DMG, Shorvon SD. Epileptic seizures in a population of 6000: 1. Demography, diagnosis and classification, and the role of the hospital services. 2. Treatment and prognosis. Br Med J 1983, 287:641-647.

7. Iani C, Fusco L, Faedda MT, Perugino U, Manfredi M. Cardiac frequency changes during absences and partial complex seizures. In advance in epileptology, Vol 17. New York: Raven Press, 1989: 340-342.

8. Johnson LC, Davidoff RA. Autonomic changes during paroxysmal EEG activity. Electroenceph Clin Neurophysiol 1964, 17:25-35.

9. Keilson MJ, Hauser WA, Magrill JP. Electrocardiographic changes during eletrographic seizures. Arch Neurol 1989, 46:1169-1170.

10. Klenerman P, Sander JWAS, Shorvon SD. Mortality of epilepsy: a study of patients in long-term care. J Neurol Neurosurg Psychiatry 1993, 56:149-152.

11. Leestma JE, Walczak T, Hughes JR et al. A prospective study of sudden death in epilepsy. Ann Neurol 1989, 26:195-203.

12. Lieb JP, Walsh GO, Babb TL, Walter RD, Crandall PH. A comparison of EEG seizure patterns recorded with surface and depth electrodes in patients with temporal lobe epilepsy. Epilepsia 1976, 17:137-160.

13. Mameli $P$, Mameli $O$, Tolu E et al. Investigation into whether neurogenic cardiovascular alterations are involved in sudden epileptic death. In Advance in epileptology, Vol 17. New York: Raven Press, 1989: 347-350.

14. Munson M. Death in epilepsy. Medical record 1910, 77:68-72.

15. Nashef L, Sander JWAS, Fish DR, Shorvon SDS. Incidence of sudden unexpected death in an outpatient cohort with epilepsy at tertiary referral centre. J Neurol Neurosurg Psychiatry 1995 (in press).

16. Nashef L, Sander JWAS. The mortality of epilepsy. In Pedley TA, Meldrum BS (eds). Recent advances in epilepsy, Vol 6. Edinburgh: Churchill Livingstone, 1995 (in press).

17. Nousiainen U, Mervaala E, Ylinen A, Uusitupa M, Riekkinen $P$. The importance of the electrocardiogram in ambulatory electroencephalographic recordings. Arch Neurol 1989, 46:1171-1174. 
18. Rosen M, Lisak R, Rubin IL. Diphenylhydantoin in cardiac arrhythmias. Am J Cardiol 1967, 18:674-678.

19. Sander JWAS, Shorvon SD. Incidence and prevalence studies in epilepsy and their methodological problems: a review. J Neurol Neurosurg Psychiatry 1987, 50:829-839.

20. Schott GD, McLeod AA, Jewitt DE. Cardiac arrhythmias that masquerade as epilepsy. Br Med J 1977 , 1:1454-1457.

21. Scott CA, Fish DR. Ictal motor phenomena in patients with temporal lobe epilepsy: clinical and pathological significance. Epilepsia 1991, 32 (Suppl 3): 95-96.

22. Walsh GO, Masland W, Goldensohn ES. Relationship between PAT and paroxysmal cerebral discharges. Bull LA Neurol Soc 1972, 37:28-35.

23. Wannmaker BB. Autonomic nervous system and epilepsy. Epilepsia 1985, 26 (Suppl 1):S31-S39.

24. Williams ER. Cardiogenic syncope and epilepsy. Postgrad Med J 1967, 43:677-679. 